\title{
Fostering pre-service teachers' theoretical knowledge application: studying with and without text-based cases
}

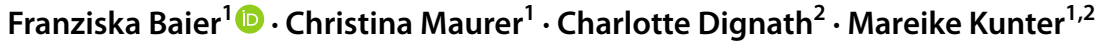

Received: 17 March 2020 / Accepted: 11 August 2021 / Published online: 22 September 2021

(c) The Author(s) 2021

\begin{abstract}
As knowledge derived from scientific theory can be helpful for teachers to reflect on their everyday teaching, universities have the challenging task of teaching this knowledge in such a way that pre-service teachers are able to apply it to their later teaching. Casebased learning has emerged as a promising method to foster pre-service teachers' scientific knowledge application throughout university teacher education. However, surprisingly, empirical evidence for its effectiveness as compared to more traditional instructional interventions in teacher education is still inconclusive, partly being due to constraints concerning the employed comparison groups. The present quasi-experimental study (conducted in the field of classroom management) investigated the effect of studying exactly the same theoretical content with and without text-based cases on scientific knowledge application (as measured by a vignette test) in a sample of 101 pre-service teachers. Although the study found a small advantage for the case-based learning group, it demonstrated that scientific knowledge application may also be effectively fostered in a more traditional instructional course. The findings and their implications are discussed against the background of cognitive theories on inert knowledge and how to prevent it in teacher education.
\end{abstract}

Keywords Case-based learning · Inert knowledge $\cdot$ Theory-practice gap $\cdot$ Pre-service teacher education $\cdot$ Classroom management

Franziska Baier

baier@psych.uni-frankfurt.de

Charlotte Dignath

dignath@dipf.de

Mareike Kunter

kunter@dipf.de

1 Goethe University Frankfurt, Theodor-W.-Adorno-Platz 6, 60629 Frankfurt, Germany

2 Leibniz Institute for Research and Information in Education, Rostocker Straße 6, 60323 Frankfurt, Germany 


\section{Introduction}

Applying knowledge from scientific theories to their own teaching practice can be useful for teachers to improve their classroom instruction (Mostert, 2007; Zottmann et al., 2013). However, teachers often struggle to systematically apply these theories to their practice (Augsdörfer \& Casper, 2018). This phenomenon has been described as the theory-practice gap (Blomberg et al., 2013; Blömeke et al., 2008), with empirical studies underlining its significance (Allen, 2009; Siebert, 2005). One possible explanation for this lack of knowledge application is that university courses may not be optimally designed (e.g. in terms of instructional design/methods) to convey relevant scientific theories in such a way that (preservice) teachers are able to use them later on in their work (Blomberg et al., 2013). Thus, the knowledge pre-service teachers develop during formal teacher education remains inert (Gruber et al., 2000; Schelfhout et al., 2006). The phenomenon of inert knowledge is well known and has been observed across many instructional settings (Renkl et al., 1996).

In particular, effective classroom management (e.g. preventing student misbehaviour) is often seen as a challenge by beginning teachers who feel that they are not well enough prepared in this area throughout their formal teacher education (Dicke et al., 2014; Veenman, 1984). Fostering pre-service teachers' application of knowledge about classroom management is of high relevance as effective classroom management is positively related to students' cognitive and motivational outcomes (Hattie, 2009; Korpershoek et al., 2016).

In order to overcome the inert knowledge problem and help bridge the theory-practice gap, studying with complex real-world classroom cases based on texts or videos has been suggested as a promising method and has been increasingly applied by teacher educators (Mostert, 2007; Syring et al., 2016). Case-based learning has also gained popularity because it has been reasoned to have positive effects on students' study motivation (and not only on their knowledge application; e.g. Hmelo-Silver, 2004) which seems generally important for students' long-term appreciation of university teacher education (Palmer, 2004). However, empirical evidence as to whether cases are indeed more effective in fostering the application of scientific knowledge than more traditional instructional methods is not yet convincing.

To close this research gap, the present study used a quasi-experimental pre-post-test design with 101 pre-service teachers to investigate whether case-based learning with texts is motivating for pre-service teachers and, more importantly, whether it helps to bridge the research-practice-gap by fostering the productive application of scientific theory to authentic text-based classroom situations.

\section{The nature of knowledge developed throughout formal teacher education}

Classroom management knowledge is an important aspect of general pedagogical knowledge (Shulman, 1987). Effective classroom management entails the prevention of classroom disruptions, the establishment of a positive classroom environment, the maintenance of momentum and the support of students with behavioural difficulties (e.g., Emmer et al., 1980; Marzano et al., 2003). Thus, classroom management knowledge is the knowledge about scientific theories on these aspects (informed by insights from practice) and how these theories translate into teaching behaviours in complex classroom situations (Gold \& Holodynski, 2015). University teacher education usually addresses this knowledge about scientific theories (Blomberg et al., 2013). However, students often are not able to apply 
this knowledge to real-world classroom problems. This means their knowledge remains inert and tends to be purely declarative, consisting of facts and principles only (see de Jong \& Ferguson-Hessler, 1996). The described phenomenon of inert knowledge may have different causes (Korthagen \& Kessels, 1999); one explanation for the inert knowledge problem may be deficits in the knowledge itself, such as insufficient conceptual knowledge (deep-level understanding) or knowledge compartmentalization (Renkl et al., 1996). Knowledge compartmentalization can mean that pre-service teachers are not able to connect what they have learned in formal teacher education about classroom management to real teaching situations because the two aspects are stored in different memory compartments (Renkl et al., 1996). For example, pre-service teachers may have studied concepts on how to effectively organize a classroom (e.g. Emmer et al., 1980) at university. When it comes to real classroom teaching, however, they organize their classroom based on their real-world experiences and observations of how a classroom is usually organized. Even though they know of both ways of organizing a classroom, the two concepts are not integrated and stand side by side (Renkl et al., 1996).

Another set of explanations for the inert knowledge problem stems from situated cognition models. From this perspective, the implementation of effective classroom management is only likely if the instructional situation, in which pre-service teachers learned classroom management strategies, does not differ too widely from the situation in which they have to use them later on (Brown et al., 1989; Renkl et al., 1996). Thus, the university context, in which pre-service teachers acquire their classroom management skills (e.g. by reading textbooks), may differ too widely from the teaching contexts in which they should apply these skills (e.g. when standing in front of a class).

\section{Case methods as a means to foster scientific knowledge application \& motivation}

Several approaches, for example deliberate practice or case-based learning (Bronkhorst, 2013; Merseth, 1996), have been developed to prevent the described problem of inert knowledge. The present study will focus on one of them, namely case-based learning.

Often cases are understood to be the documentation of a real-life event or situation (Merseth, 1996; Zottmann et al., 2013); they usually provide rich information on the context, the participants and the reality of the situation (Merseth, 1996). Cases are usually employed either to illustrate how theory can be applied to realistic teaching situations or to promote problem-solving skills by analysing complex and ill-defined classroom situations (Moreno \& Valdez, 2007). The latter is usually a major aim and defining feature of problem-based learning, which can be understood as a specific subset of case-based learning (Zottmann et al., 2013). In particular, when cases are being employed to enhance learners' problem-solving skills, researchers have emphasized and shown the importance of instructional support (Goeze et al., 2014).

Case methods seek to foster the transformation of declarative knowledge into procedural knowledge as scientific theories are explicitly studied against the background of and related to real-world teaching situations (Renkl et al., 1996). This situatedness of learning is not only supposed to foster the ability to apply scientific knowledge, but also study motivation (Moreno \& Valdez, 2007). Here, the rationale is that if the pre-service teacher study with real-world situations that are meaningful in terms of their later profession as a teacher, this should have positive effects on their general study motivation and situational interest during learning (Harackiewicz \& Knogler, 2017; Moreno \& Valdez, 2007; Wigfield \& Eccles, 2000). Situational interest (or state interest) combines positive affective qualities 
such as feelings of enjoyment with cognitive qualities such as perceptions of value and personal importance (Harackiewicz \& Knogler, 2017; Hidi \& Renninger, 2006). On a more basic level, experiencing the usefulness of scientific theory in the context of solving realworld classroom situations should foster pre-service teachers' general intensity of using this knowledge besides their ability to apply it productively.

\section{Different ways of presenting cases in initial teacher education}

Cases may be presented by means of written text or video (Moreno \& Valdez, 2007; Yadav et al., 2011). Video-based cases are complex, since many events happen at the same time, whilst text-based cases are sequential (Syring et al., 2016). Therefore, text-based cases may initially be better suited for pre-service teachers who have a lower level of expertise in teaching (Syring et al., 2016). However, video cases may be more motivating as they are more authentic (Syring et al., 2016). In conjunction with the employment of and research into video-based cases, the conception of a teacher's professional vision has emerged (Sherin, 2007). Professional vision is defined as the ability to perceive critical events (noticing) and the ability to interpret these events based on theory (knowledge-based reasoning; Stürmer et al., 2013). Thus, when (pre-service) teachers engage in knowledgebased reasoning, they reflect on how the theory they have learnt relates to the practice they observe on the video and thereby prevent inert knowledge (Stürmer et al., 2013). Many empirical studies on case-based learning with videos have operationalized scientific knowledge application by drawing on professional vision and knowledge-based reasoning (e.g. Gold et al., 2013; Kramer et al., 2017). Studies on case-based learning with texts have, of course, not drawn on the conception of professional "vision" but rather investigated knowledge application without this specific framing (Moreno \& Valdez, 2007).

\section{Empirical evidence on the effectiveness of case-based learning}

Effects on knowledge application There is limited and mixed empirical evidence for the effectiveness of case methods for developing pre-service teachers' ability to apply scientific knowledge when compared to other forms of instruction (Blomberg et al., 2013; Krammer, 2014). Some recent studies (all of which investigated video cases) have found positive effects of studying with video cases in teacher education on relevant outcome measures such as knowledge-based reasoning. Hmelo-Silver et al. (2009), for example, showed that pre-service teachers studying in an online problem-based learning environment with video cases, as compared to pre-service teachers studying in traditional textbook-based courses, were better able to apply their knowledge in a later video task. Investigating professional vision specifically in the area of classroom management, Hellermann et al. (2015) showed that pre-service teachers in both treatment groups (studying with their own videos and/or other teachers' videos) had a significantly higher increase in their professional vision than the comparison group. Likewise, in another study on a video-based training with cases in classroom management with pre-service teachers, the video-cases-group significantly increased its professional vision when compared to the comparison group (Gold et al., 2013).

However, there are also studies that have not found any significant difference in outcome measures between pre-service teachers who studied with or without cases. Schrader et al. (2003) investigated the effectiveness of different forms of instruction, either traditional (readings, presentations, field experiences), or traditional plus commercial videos or traditional combined with online-delivered multimedia cases on the pre-service teachers' 
understanding of early literacy instruction. They did not find any significant differences between the groups in terms of their performance in a concept mapping task. Stürmer et al. (2013) investigated pre-service teachers in a pre-post-test design that participated in three different teacher education courses with different contents from pedagogy. Only in one of the courses did the pre-service teacher study with contextualized cases based on classroom videos. However, the other two groups also reflected on how the theoretical knowledge acquired can be applied to realistic problems to some extent. The results showed that all groups significantly increased their overall professional vision and that these increases did not differ across groups.

Thus, previous studies have revealed inconclusive results concerning the effectiveness of case-based learning. Furthermore, the scope of the available findings is limited because of constraints concerning the employed comparison groups. In some studies, case-based learning was compared to conditions that differed in multiple ways from the treatment conditions (e.g. Stürmer et al., 2013) or no further information was given on the exact instructional methods applied in the comparison group (e.g. Hmelo-Silver et al., 2009). In the studies conducted by Hellermann et al. (2015) and Gold et al. (2013) the comparison groups did not systematically receive any specific classroom management intervention. Therefore, no conclusion could be drawn as to whether studying specifically with cases had increased the treatment group's professional vision in classroom management. Overall, despite the high theoretical expectations held for case-based learning, the empirical evidence for its effectiveness as compared to other interventions is not yet convincing. This is especially emphasized by Blomberg et al. (2013), as well as Krammer (2014), who state that studies with (quasi-)experimental designs and larger sample sizes are lacking.

Effects on motivation Empirical evidence in terms of students' study motivation is much more conclusive. Indeed, there is ample empirical evidence that studying with cases is positively related to students' study motivation across different domains (Hmelo-Silver, 2004; Thistlethwaite et al., 2012). Researchers have also found these effects specifically for teacher education when studying with cases, particularly when studying with video-based cases (Kramer et al., 2017; Moreno \& Valdez, 2007).

\section{(Pre-service) teachers' experience-based knowledge and case-based learning}

The previous section discussed how the application of evidence-based knowledge about classroom management can be fostered by means of case-based learning. The resulting increased intensity and quality with which this scientific knowledge may be applied after having studied with cases prompts the question of how this impacts pre-service teachers' usage of other knowledge source that they may also rely on when confronted with classroom situations. Research has distinguished knowledge derived from scientific theory (also called formal knowledge) from knowledge derived from one's own experiences as a teacher (also called practical knowledge; Fenstermacher, 1994). The latter can be, but does not necessarily have to be, in line with what scientific evidence suggests to be effective teaching (Leikin \& Levav-Waynberg, 2007; Zeichner, 1980). Different studies have shown that teachers rely on their practical experiences, rather than on their research-based knowledge, when it comes to everyday teaching situations (e.g. Allen, 2009; Franke \& Wecker, 2017). In terms of case-based learning, the studies presented in the previous section did not investigate whether case-based learning also affects the degree of usage of other kinds of knowledge (like experience-based knowledge) when specifically theory-based knowledge 
usage was fostered. On the one hand, it seems plausible that the intensified usage of scientific knowledge reduces the degree to which already gained experience-based knowledge is used because the former has become more prominent and is now easier to access from memory (Potvin, 2013). On the other hand, it seems plausible that experience-based knowledge is still used with the same intensity because it can be activated independently of the newly learned scientific knowledge and is usually automated (tacit) knowledge that can easily be applied and is still highly valued by the pre-service teachers (Allen, 2009; de Jong, \& Ferguson-Hessler, 1996).

\section{The present study}

First of all, the present study aims at investigating if case-based learning with texts fosters pre-service teachers' ability to apply scientific theory to authentic classroom situations in formal teacher education. The present study focuses on learning from text-based cases as text-based cases are easy to be constructed and implemented and seem well-suited for pre-service teachers who are not experts yet (Syring et al., 2016). As the implementation of effective classroom management presents an especially high challenge for beginning teachers (Chaplain, 2008), the present study focuses on knowledge development in this area. An important element in this study is the quasi-experimental approach, which features a meaningful comparison group that receives a highly comparable intervention so that specifically the effect of cases can be studied. In addition to knowledge application, the present study also considers the students' intrinsic motivation during the intervention as an outcome measure, building on the positive effects found in previous studies (e.g. Hmelo-Silver, 2004). We focus on the motivational construct of situational interest, which researchers define as the motivational state of an individual evoked by the incentive structure of a (learning) environment (Durik \& Harackiewicz, 2007; Krapp, 2010). This state of interest combines feelings of enjoyment and perceptions of value and personal importance (Harackiewicz \& Knogler, 2017).

Furthermore, the present study seeks to find out to what degree pre-service teachers report relying on their theory-based knowledge and their practical experiences when confronted with authentic classroom situations after having practiced applying scientific theory to cases. As already stated, practical teaching experiences have been shown to strongly guide teachers' behaviour in the classroom (Allen, 2009; Franke \& Wecker, 2017).

Two different online learning environments were implemented, one in which pre-service teachers studied with theoretical input and applied it to real-world text-based cases (treatment group) and one in which pre-service teachers studied with the same theoretical input and applied it to abstract theoretical models (comparison group). Thus, in the treatment group the link to real-world classroom cases should prevent knowledge compartmentalization and thereby inert knowledge. The application of knowledge to (additional) theoretical models was used as a task in the comparison group to realize a comparable complex tasks like that in the treatment group that would also require further usage of the information from the theoretical texts but not include any link to real-world situations. Both groups received instructional support in the form of sample solutions and additional theoretical input and studied with more than one case or theoretical model (multiple contexts). Thus, both groups received a comparably high-quality instructional intervention except for the factor be manipulated. An online learning environment was chosen to reduce instructor/experimenter bias (higher degree of standardization of material, interactions and 
instructions; Reips, 2000) and to provide students with higher flexibility as to where and when they study.

\section{Research questions and hypotheses}

The present study investigated the following four research questions and tested the following three hypotheses.

RQ1: Does case-based learning have a positive effect on pre-service teachers' ability to apply scientific knowledge (as measured by a performance-based vignette test)?

H1 Pre-service teachers, who have studied with text-based cases, demonstrate a higher degree of productive scientific knowledge application (in a performance-based vignette test) than pre-service teachers who have not studied with such cases.

RQ2: Does case-based learning have a positive effect on pre-service teachers' situational interest?

H2 Pre-service teachers, who have studied with text-based cases, report having experienced higher situational interest (in the post-test) than pre-service teachers who have not studied with such cases.

RQ3a: Does case-based learning have a positive effect on the rate of scientific knowledge usage?

H3a Pre-service teachers, who have studied with text-based cases, demonstrate a higher increase in their self-reported rate of using scientific theory than pre-service teachers who have not studied with such cases.

RQ3b: Does case-based learning have any effect on pre-service teachers' self-reported rate of using their knowledge from their own practical experiences?

The present study did not formulate a hypothesis for his last research question as it wanted to investigate the effect of case-based learning on experience-based knowledge usage in an exploratory way.

\section{Method}

\section{Sample and design}

In the present study, 101 pre-service teachers participated, 51 in the treatment group and 50 in the comparison group. The sample was one of convenience. The treatment group consisted of pre-service teachers ( $n=40$ females) who had attended a course on classroom management in the context of initial teacher education in a German university. Participants in the comparison group ( $\mathrm{n}=41$ females) took the same course (except for the intervention) half a year later. The pre-service teachers did not receive any grades in any of the two courses and were free to choose another course in the first week of the semester, if they did not wish to be part of a research study. Participants of both groups prepared for different 
school types: $32.7 \%$ preparing for primary school, $44.6 \%$ preparing for lower and middle secondary track, $13.9 \%$ preparing for the highest secondary track and $8.9 \%$ preparing for special education. Most participants were enrolled in their third or fourth semester of their university studies $(M=3.56, S D=2.07)$. In total, $89 \%$ of participants had some type of prior teaching experience (e.g. internships).

The study had a quasi-experimental design including pre- and post-test measures. Pretest and post-test questionnaires were administered as paper-pencil formats in a whole group setting in the second and sixth week of the courses, respectively. Filling in the questionnaires took approximately $30 \mathrm{~min}$. As the first author was the instructor of the two courses, the intervention was implemented online by providing a digital learning environment for three weeks (weeks three to five with respect to the start of the term) to reduce experimenter bias. The participants were blind to the hypotheses.

\section{Procedure and material}

Both groups studied with the online material for three weeks and had to submit three assignments (one per week). Figure 1 depicts an overview of the design of the study. Each week, participants had to complete the same pattern of tasks; firstly, participants had to read a theoretical input on classroom management (4 pages) and then summarize its content. The first author of this study wrote these theoretical texts. She drew the contents from several textbooks and guidebooks on effective classroom management presenting scientific theories, empirical findings and guidance. The theoretical inputs focused on aspects such as Kounin's theory on discipline and group management (Kounin, 1970), theories on maintaining good student behaviour by using positive/negative consequences (Emmer et al., 2003; Landrum \& Kauffman, 2006) and theories and strategies on how to support highneeds students (e.g. Marzano et al., 2003).

After having read and summarized the theoretical input, participants in the treatment and comparison groups received different tasks, respectively. Participants in the treatment group studied with two real-world text-based cases from the area of classroom management (chosen beforehand by the first author) every week. These cases were stored in a Wiki database and participants had to generate possible courses of action for the respective textbased cases.

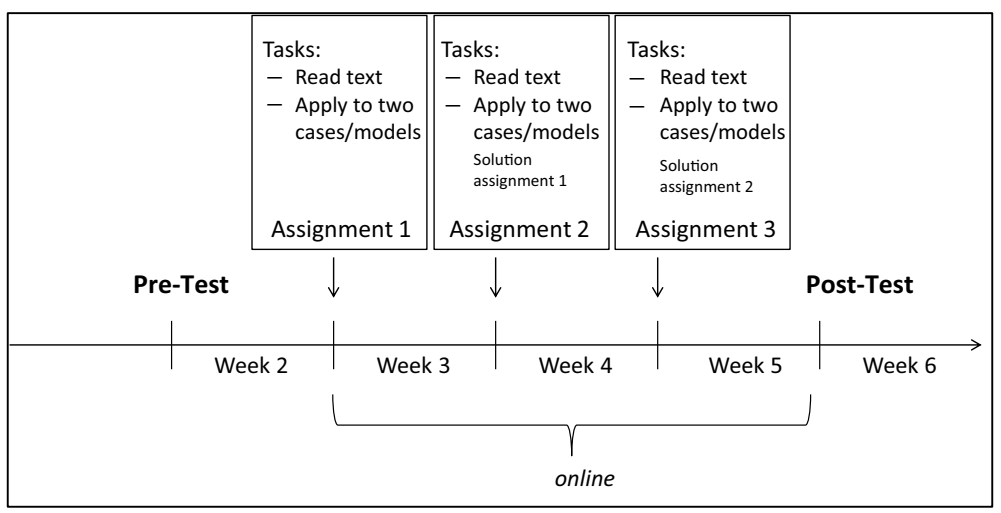

Fig. 1 Study design 
The first author had collected the text-based cases with a different group of pre-service teachers. Each student had implemented a real-world case that they had experienced or witnessed. The text-based cases represented complex situations of classroom disruptions including several students or complex situations with single students displaying behavioural problems. Appendix A shows an example of such a text-based case.

Participants in the comparison group studied with two complex theoretical models of classroom management instead of the cases and had to relate the theoretical texts to these two models. Thus, they needed to reflect on the theoretical input derived from the texts against the background of more complex models of classroom management. The theoretical models were provided to the comparison group via a conventional learning management system as this group was not required to study with the cases that the Wiki database provided.

In both groups, participants had one week to complete each assignment before they received the assignment for the next week. Participants had to answer all tasks per assignment on two pages in total. After assignments 1 and 2, respectively, the first author made available sample solutions covering the application of the theoretical input to the text-based cases/theoretical models to the pre-service teachers. She informed the participants via e-mail with respect to the upload of the sample solutions and gave them the opportunity to read them. However, reading the solutions was not obligatory. Participants in both groups had the opportunity to access the sample solutions and the theoretical inputs from the previous sessions as well as some additional theoretical input (e.g. theory on how classroom conflicts arise) at any time throughout the intervention (instructional support). Except for uploading the assignments and the sample solutions and except for checking as to whether all students had submitted their assignments, no interaction between the lecturer and the students took place during the intervention. In the course weeks after the to-be-evaluated intervention, the comparison group also studied with cases so that this group also received the treatment that is thought to be more advantageous.

\section{Instruments}

The pre-test questionnaire assessed pre-service teachers' productive application of classroom management knowledge to authentic classroom situations (performance-based vignette test), their self-reported theory-based and experience-based knowledge usage and their socio-demographic variables. The post-test questionnaire again presented the performance-based vignette test and assessed the students' self-reported theory-based and experience-based knowledge usage. In addition, it assessed pre-service teachers' intrinsic motivation while having studied with the cases/the models and included a manipulation check.

\section{Manipulation check: theory-practice connection}

Pre-service teachers rated, on a self-constructed 6-point Likert scale (from 1-strongly disagree to 6- strongly agree), whether they found that, during the intervention, theory had been connected to practice. The scale consisted of three items and was rated by the participants as part of the post-test questionnaire. An example of one such item is: "During the intervention it became clear how theoretical concepts apply to practice". The Omega coefficient (McDonald, 1999; measure of internal consistency) of the scale was 0.87 . 


\section{Ability to apply classroom management knowledge (performance-based vignette test)}

In order to measure the degree to which pre-service teachers were able to apply scientific knowledge on classroom management productively to authentic classroom situations, a vignette test was developed. The test was comprised of four text vignettes describing typical classroom situations from the area of classroom management, such as dealing with classroom disruptions, off-task behaviour or aggression (Khasinah, 2017). The vignettes were developed based on typical reports of these types of misbehaviours from teachers as found in textbooks or databases (e.g. Nolting, 2002; University of Münster, 2020). Appendix B presents the vignette test. Pre-service teachers were asked to provide options for teacher action for each vignette (a large blank space below each vignette was supposed to invite them to provide several options). If pre-service teachers applied their scientific knowledge of classroom management productively, this would result in a higher number of options of teacher action in line with scientific theory and classroom management experts' suggestions.

The pre-service teachers' answers to the four text vignettes were analysed using quantitative content analysis (Berelson, 1952; Krippendorff, 1989). The first author deductively developed a standardized coding scheme for each vignette, including adequate and inadequate options for teacher action to the presented situations according to scientific theory (the categories). As the classroom situations were complex, there were always several useful options of teacher action (that could be taken in parallel). Furthermore, two experts in classroom management (with substantial knowledge about scientific theory, but also practical experience), who were not involved in the present study, were asked to provide potential options for teacher action to the four classroom situations. The first author added these options (if new) to the coding scheme. In a further step, the coding scheme was tested and inductively revised based on the answers of pre-service teachers in two pilot studies. Appendix $\mathrm{C}$ shows an excerpt of the coding scheme for vignette 2. A trained master coder first segmented the material of the present study into meaningful chunks and subsequently coded it based on the coding scheme. A second trained coder (reliability coder) independently coded twenty per cent of the material to establish interrater-reliability (Syed \& Nelson, 2015). Inter-rater reliabilities (Cohen's kappa coefficient) were at least satisfactory for all vignettes: $\kappa_{\mathrm{cv} 1}=0.87, \kappa_{\mathrm{cv} 2}=0.94, \kappa_{\mathrm{cv} 3}=0.87, \kappa_{\mathrm{cv} 4}=0.77$.

Participants' answers were evaluated based on the coding scheme and subsequently quantified. Participants received one point for each (qualitatively different) answer being in line with scientific theory on classroom management (see Appendix C). Participants received half a point for answers that were derived from scientific theory, but were not specific to the classroom situation under consideration (see Appendix C). Participants received no points for wrong answers, i.e. answers that either contradicted scientific theory or answers that were in line with scientific theory but inadequate in the classroom situation under consideration (thus being the wrong application of theory; see Appendix C).

For each participant, a sum score was calculated across the four text vignettes at the post-test. The internal consistency of the vignette test at the post-test was $\Omega=0.67$. At the pre-test, however, the test's internal consistency was not satisfactory $(\Omega=0.27)$. Calculating a sum score at the pre-test was, thus, not reasonable and the score on each text vignette was included individually as a covariate in an analysis of covariance. Other authors (e.g. Berger \& Hänze, 2015; Bretz \& McCLary, 2014; Hellermann et al., 2015) have described the same difficulty (low internal consistency at the pre-test). Low reliabilities are especially evident with performance assessments (Bacon, 2004) and may be due to the participants' 
Table 1 Descriptive statistics and effect sizes for the vignettes

\begin{tabular}{|c|c|c|c|c|c|c|c|}
\hline & \multicolumn{3}{|l|}{ Pre } & \multicolumn{3}{|l|}{ Post } & \multirow[b]{2}{*}{$d$} \\
\hline & $M$ & $S D$ & range & $M$ & $S D$ & range & \\
\hline \multicolumn{8}{|c|}{ Vignette 1} \\
\hline TG & 1.03 & 0.77 & $0.00-3.00$ & 1.43 & 0.78 & $0.00-3.00$ & 0.40 \\
\hline $\mathrm{CG}$ & 0.78 & 0.74 & $0.00-3.00$ & 1.03 & 0.70 & $0.00-2.50$ & 0.39 \\
\hline \multicolumn{8}{|c|}{ Vignette 2} \\
\hline TG & 1.50 & 0.88 & $0.00-3.50$ & 2.79 & 1.34 & $0.00-5.50$ & 1.14 \\
\hline $\mathrm{CG}$ & 1.41 & 0.86 & $0.00-3.50$ & 2.23 & 1.11 & $0.00-5.00$ & 0.65 \\
\hline \multicolumn{8}{|c|}{ Vignette 3} \\
\hline TG & 0.40 & 0.42 & $0.00-2.25$ & 1.96 & 1.26 & $0.00-5.00$ & 2.85 \\
\hline $\mathrm{CG}$ & 0.64 & 0.76 & $0.00-4.50$ & 1.69 & 1.03 & $0.00-3.50$ & 1.28 \\
\hline \multicolumn{8}{|c|}{ Vignette 4} \\
\hline TG & 1.55 & 1.08 & $0.00-4.00$ & 2.06 & 1.36 & $0.00-6.00$ & 0.40 \\
\hline $\mathrm{CG}$ & 1.44 & 1.01 & $0.00-4.00$ & 2.18 & 1.29 & $0.00-6.00$ & 0.64 \\
\hline \multicolumn{8}{|c|}{ Vignette test } \\
\hline TG & - & - & - & 8.24 & 3.35 & $0.00-16.00$ & - \\
\hline $\mathrm{CG}$ & - & - & - & 7.13 & 2.93 & $1.75-15.50$ & - \\
\hline
\end{tabular}

$\mathrm{d}=$ Cohen's d (effect size pre/post intervention); $T G$ Treatment Group, CG Comparison Group

lack of a coherent knowledge base prior to any instruction. Table 1 shows the mean scores across participants for each of the four vignettes (and the mean sum score across all vignettes at the post-test).

\section{Intrinsic motivation - situational interest}

Items from two subscales from the Intrinsic Motivation Inventory (Deci \& Ryan, 2003) assessed pre-service teachers' affective and cognitive situational interest at the post-test. The two subscales originally tap affective aspects of situational interest (in total 7 items) and cognitive aspects of situational interest (in total 7 items), respectively. To keep the testing more economical, one common scale consisting of 4 items from the affective subscale and 3 items from the cognitive subscale was constructed and the items were adapted to the study context. Participants responded to the items on a 6-point Likert scale, ranging from 1-strongly disagree to 6- strongly agree. An example item is: 'I enjoyed studying with the online material very much'. The Omega coefficient was 0.88 .

\section{Self-reported theory-based and experience-based knowledge usage}

To assess the degree to which pre-service teachers rely on their knowledge from either scientific theory or personal experiences (when analysing classroom situations), self-report scales were used in the pre- and post-test. Participants gave their answers on a six-point Likert-scale, ranging from 1-strongly disagree to 6- strongly agree. The two scales (theory-based analysis/experience-based analysis) consisted of two items each. The items of the scale on theory-based analysis are: 'When analysing a classroom situation, I draw on theories from classroom management' and 'When confronted with a classroom situation, 
I think about which teacher actions classroom management theory would suggest'. The Omega coefficient of this scale was 0.81 in the pre-test and 0.91 in the post-test. The items of the scale on experience-based analysis are: 'When analysing a classroom situation, I draw on my own practical experience' and 'When confronted with a classroom situation, I consider options of teacher action based on my own experiences from practice'. The Omega coefficient of this scale was 0.94 in the pre-test and 0.97 in the post-test.

\section{Data analysis}

An analysis of covariance (RQ1), an independent samples t-test (RQ2) and repeated-measures variance analyses (RQ3a/RQ3b) were conducted in SPSS (Version 25). Prior testing suggested that the assumptions for the respective analyses were sufficiently met (normal distribution, variance homogeneity, independence of the covariates and the treatment effect). For all of the hypotheses (H1-H3a), one-tailed hypothesis tests (as directed hypotheses had been formulated) were employed. Research question $3 \mathrm{~b}$ was tested two-sided. The significance testing was performed at the 0.05 level.

\section{Results}

\section{Preliminary analysis \& manipulation check}

Participants in the treatment group did not differ significantly from participants in the comparison group in terms of gender $\left[\chi^{2}(1)=0.07, p=0.80\right]$, semester of university study $[t(99)=-1.73, p=0.09]$, school type $\left[\chi^{2}(3)=1.82, p=0.61\right]$, high school GPA $[t(99)=-1.24, p=0.22]$ and teaching experience $\left[\chi^{2}(1)=0.081, p=0.78\right]$. As the groups were comparable in all assessed control variables, these variables were not included in further analyses.

The groups did not show statistically significant differences in terms of their productive scientific knowledge application in vignettes 1, 2, 3 and 4 in the pre-test [vignette 1: $t(99)=1.66, p=0.10, d=-0.33$; vignette $2: t(99)=0.52, p=0.61, d=-0.10$; vignette 3 : $t(76,7)=-1.98, p=0.051, d=0.40$; vignette $4: t(99)=0.52, p=0.60, d=-0.10]$. Moreover, participants did not differ in their self-reported theory-based and experience-based analyses in the pre-test [theory-based: $t(92)=1.30, p=0.20, d=0.25$; experience-based: $t(94)=-1.05, p=0.30, d=0.23]$.

An independent samples t-test tested whether participants of the treatment group perceived their intervention as more strongly relating theory to practice than the comparison group (manipulation check). Results showed that the treatment group reported higher theory-practice connection than the comparison group $[t(96)=2.20, p=0.03, d=0.42]$.

\section{Effect of case-based learning on productive knowledge application (RQ1)}

Results of an analysis of covariance showed a statistically significant effect for the factor group $\left[F(1,93)=3.41, p=0.04, \eta_{p}^{2}=0.04\right]$. Thus, in line with expectations $(\mathrm{H} 1)$, the treatment group showed a higher level of productive knowledge application after the intervention than the comparison group in the vignette test, when controlled for performance in the individual vignettes at the pre-test. However, the effect size was small. 
Table 1 shows that both groups had partly similar gains in their productive application of classroom management knowledge from the pre- to the post-test in the individual text vignettes. The effect sizes for the measurement point are mostly medium or high for both groups.

\section{Effects of case-based learning on situational interest (RQ2)}

In line with expectations, the results of an independent samples t-test revealed that the treatment group reported significantly higher situational interest $[t(99)=3.10, p=0.00$, $d=0.61$ ] than the comparison group with a medium effect size $(\mathrm{H} 2)$. Table 2 presents descriptive statistics.

\section{Results on theory-based and experience-based analysis (RQ3a/RQ3b)}

The results of a repeated measures ANOVA showed that both groups reported drawing more strongly (large effect size) on their theoretical knowledge when analysing classroom situations after the interventions $\left[F(1,90)=74.68, p=0.00, \eta_{p}^{2}=0.45\right]$. However, contrary to expectations (H3a), the treatment group did not show a higher increase in self-reported theory-based analysis of classroom situations than the comparison group $[F(1,90)=0.03$, $\left.p=0.44, \eta_{p}^{2}=0.00\right]$.

The present study further investigated the degree to which pre-service teachers reported relying on their knowledge from their own experiences when generating solutions to classroom situations. The results of a repeated measures ANOVA showed that there was no change from the pre-test to the post-test in any of the two groups $[F(1,93)=0.34, p=0.56$, $\left.\eta_{p}^{2}=0.00\right]$ and no significant interaction between group and measurement point $[F(1$, $\left.93)=0.23, p=0.63, \eta_{p}^{2}=0.00\right]$. The descriptive results in Table 2 show that the empirical means of the scale are positive (equal to or above 4 on a 6-point Likert scale) for both groups at both measurement points, meaning that both groups rely on their own experiences when analysing authentic classroom situations.

Table 2 Descriptive statistics of the self-report measures

\begin{tabular}{llllllll}
\hline & Pre & \multicolumn{3}{l}{ Post } \\
& $M$ & $S D$ & & $M$ & $S D$ & $d$ \\
\hline Theory-based knowledge usage & & & & & \\
TG & 3.51 & 1.02 & 4.68 & 0.76 & 0.80 \\
CG & 3.20 & 1.17 & 4.42 & 0.80 & 0.78 \\
Experience-based knowledge usage & & & & & \\
TG & 4.09 & 1.22 & 4.08 & 1.22 & -0.01 \\
CG & 4.36 & 1.09 & 4.24 & 1.27 & -0.13 \\
Situational interest & & & & & \\
TG & - & - & 4.99 & 0.61 & - \\
CG & - & - & 4.61 & 0.63 & - \\
\hline
\end{tabular}

$\mathrm{d}=$ Cohen's d (effect size pre/post intervention); $T G$ Treatment Group, $C G$ Comparison Group 


\section{Discussion}

The present study found that case-based learning was slightly more effective in fostering pre-service teachers' productive knowledge application than a similar intervention without cases (RQ1). Furthermore, pre-service teachers studying with cases reported having had higher situational interest while studying (RQ2). Both groups reported higher reliance on scientific theory when confronted with classroom situations after the interventions (RQ3a), but showed no change in their reliance on their practical experiences (RQ3b).

\section{Interpretation of findings}

The present study used case-based learning as a method to prevent inert knowledge and thus help bridge the research-practice gap, a prevalent problem in formal teacher education (e.g. Allen, 2009). Case-based learning has its theoretical justification in situated cognition models. As described in the Introduction, situated cognition models consider inert knowledge to be a consequence of missing congruence between the context in which classroom management is studied (e.g. in university lectures) and in which it has to be applied (e.g. in the school classroom). The results of this study suggest that studying with cases was effective in establishing this congruence by relating textbook information to real-world classroom problems (positive manipulation check).

Furthermore, the results can be interpreted as being in line with the first hypothesis and those previous empirical studies that found case-based learning to be more effective in terms of productive knowledge application than other, more theoretical and less contextualized teacher education courses (e.g. Hmelo-Silver et al., 2009). Nevertheless, the effect the present study found was small and thus may not be of practical relevance. As previous empirical evidence on the effectiveness of case-based learning in teacher education was rather limited (when compared to its high popularity) and many studies had suffered from rather weak comparison groups (e.g. Gold et al., 2013), this study provides important additional insights into the intrinsic effect of case-based learning. Many previous studies were concerned with video-based cases and the study of professional vision as outcome measure (e.g. Gold et al., 2013; Hellermann et al., 2015). Thus, the present research complements these previous studies by demonstrating that studying with text-based cases may also be suited to develop knowledge that can be applied and bridge the research-practice gap.

However, as already mentioned, the effect size for case-based learning in the present study was small and the comparison group demonstrated a substantial, partly similar gain in its productive knowledge application from the pre-test to the post-test. The fact that the comparison group also received a systematic, engaging instruction on classroom management could explain this finding. Pre-service teachers in the comparison group also had to solve tasks that required higher-order thinking; they had to relate the studied theory to more complex theoretical models. Thus, it is probable that pre-service teachers in the comparison group also gained a deep-level understanding of the theory, which is an important precondition for being able to apply the respective knowledge (Renkl et al., 1996). Moreover, studying with the input from textbooks alone could have prevented knowledge compartmentalization (and thus inert knowledge) by showing, through general recommendations for actions in the classroom, how classroom management as presented by formal teacher education connects to real teaching situations (Renkl et al., 1996). 
In line with the second hypothesis, the treatment group found the intervention to be more interesting than the comparison group. This result concurs with prior research that has shown that students experience higher situational interest (e.g. enjoyment) when studying with cases (Moreno \& Valdez, 2007; Thistlethwaite et al., 2012). Motivation theories also suggest that increasing the meaningfulness of a learning subject results in increased situational interest (Schiefele \& Schaffner, 2015). Studying with cases is a meaningful task as the cases present relevant situations that pre-service teachers will probably encounter in the future (Moreno \& Valdez, 2007).

The present study found that both groups showed a similar increase in their reported usage of theory-based knowledge from the pre-test to the post-test (RQ3a). Thus, although the treatment group showed a marginal better improvement in its ability to use this knowledge, both interventions seemed to have been effective in increasing the pre-service teachers' perceptions of more generally relying on this knowledge and accessing it when analysing classroom situations. The theoretical input pages (including general recommendations for actions in the classroom) may have been sufficient in creating a knowledge base that seems suitable to draw upon. The present study further found that both groups did not change in their experience-based analysis of authentic classroom situations (RQ3b). Thus, even though pre-service teachers relied more strongly on scientific theory after the interventions, they still reported making use of their own practical experiences. This finding is in line with theoretical assumptions and empirical findings showing that practical teaching experiences strongly seem to guide teachers' behaviour in the classroom (Franke \& Wecker, 2017). The pre-service teachers' reliance on their knowledge from their own practical experiences may be explained by the nature of this knowledge. Knowledge derived from own experiences through informal learning is usually automated (tacit) knowledge that can easily be applied (de Jong, \& Ferguson-Hessler, 1996).

\section{Strengths and limitations}

The present investigation compared studying theory and applying it to cases with studying the same theoretical contents without the application to cases but instead to theoretical models. Both groups received the same structure and timing of online assignments and completed the tasks in individual work with the same amount of instructional support. Thus, the interventions of both groups were highly comparable, except for the manipulated variable: providing information from complex real-world everyday classroom situations. This is an advantage over several previous studies from which the isolated effect of using cases on scientific knowledge application is difficult to deduce (e.g. Gold et al., 2013; Hellermann et al., 2015).

Nevertheless, the present study also has several limitations. First, the design of the study was quasi-experimental since the pre-service teachers were not assigned randomly to the two different interventions, thus, the effects of participant self-selection cannot be entirely ruled out. History effects present another threat to the study's internal validity; the comparison group engaged in the instruction six months after the treatment group and different external events may have occurred during their intervention and influenced the outcome. Maturation and re-test effects cannot be ruled out for both groups.

Secondly, the text vignettes measuring the pre-service teachers' ability to apply their scientific knowledge productively were of reduced complexity as compared to real-life classroom situations (and the text-based cases). Therefore, it cannot be concluded from the performance in the vignette test, that pre-service teachers would also apply their knowledge 
in real teaching situations in which quick decision-making is required. The present study did not consider long-term effects of the interventions on the pre-service teachers' actual teaching behaviour. It is likely, however, that pre-service teachers backdrop to their naïve conceptions and subjective theories of classroom management in stressful situations that require quick decision-making (Korthagen \& Kessels, 1999).

Finally, the vignette test could not reliably assess pre-service teachers' prior abilities to apply scientific knowledge to classroom situations. As the test had low internal consistency at the pre-test, each of the four text vignettes was included as an individual covariate rather than calculating a sum score. One reason for the low internal consistency may have been that the pre-service teachers have little knowledge about classroom management at the beginning of the course, so that their test responses were not consistent with a meaningful scale (Bacon, 2004).

\section{Implications and conclusion}

Although case-based learning was slightly more effective in the present study (RQ1), the pre-service teachers studying without cases also substantially gained in their knowledge. Therefore, case-based learning may not necessarily be the only panacea to avoid inert knowledge. Hence, future studies should explore further which other methods are also well suited to foster productive knowledge application. To this end, it seems fruitful to more strongly consider the several causes of inert knowledge suggested in the literature (e.g. insufficient conceptual knowledge, knowledge compartmentalization; Renkl et al., 1996) when designing learning environments.

Overall, the employment of text-based cases in formal teacher education appears promising as the pre-service teachers in the present study reported high situational interest (RQ2). High situational interest may have long-term positive effects on the pre-service teachers' general appreciation of formal teacher education (Palmer, 2004). Future studies should also investigate complex relationships among the different outcomes that were investigated in the present study. For example, it is possible that higher situational interest while studying with cases leads to higher (mental) effort and attention in the learning situation which in turn has a positive effect on the quality and intensity of knowledge application (Renkl et al., 1996).

As text-based cases are economical to be constructed, distributed and updated, these may be employed by a large number of teacher educators. Thus, all in all, it seems worthwhile to investigate further the effectiveness of studying with text-based classroom cases in formal teacher education.

\section{Appendix A}

\section{An example of the real-life cases that pre-service teachers in the treatment group received}

Setting: 6th grade, very heterogeneous students.

In general, the class is very loud. The students argue a lot, get up from their seats during lessons and frequently interrupt the teacher when she is explaining something. When the class gets very loud, the teacher rings a bell and counts backwards from ten. Those students, who are still talking after the countdown, receive a warning. If they have received 
several warnings, they have to copy the school rules and have to reflect on their misbehaviour. Furthermore, their parents have to sign the extra work. However, some students are indifferent concerning these measures and refuse to do their extra work. The teacher is still very young and tries to be patient. By talking individually to students after the lesson she tries to find solutions. However, it is difficult for her to stand her ground; many students know this and take advantage of the situation by disrupting the lesson again and again. This is very distracting for those students who try to learn something; they are not able to concentrate and a lot of time is wasted.

\section{Appendix B}

\section{Vignettes that were used to measure productive knowledge application}

\section{Vignette 1}

Lisa is a 3rd grade student in your class. She has bad grades in many subjects. Furthermore, she is known to many teachers as she tries over and over again to disrupt their lessons; Lisa starts to sing loudly whenever something happens she does not like. Imagine you are Lisa's teacher. What would you do in the acute situation (Lisa starts singing again, while you are explaining something at the whiteboard) and why?

\section{Vignette 2}

Tim is an 8th grade student in your class. He frequently stands up during your lessons, punches his classmates or provokes them with swear words. In addition, he is disrespectful of you as a teacher, he does not do his work and he often disrupts your lessons with interjections that have nothing to do with the current topic. How would you, as a teacher, solve this conflict in the long run?

\section{Vignette 3}

Marie and Anna are 5th grade students in your class. While you are explaining something at the whiteboard for about five minutes, Marie and Anna exchange news about their weekend in a whisper. How would you behave in this situation as a teacher and why?

\section{Vignette 4}

Mrs. Knapp's students enter the classroom, talking loudly to each other. Mrs. Knapp enters the classroom. The class does not become quieter. Mrs. Knapp raises her voice and shouts: 'I would like to start! Take your seats!' It is still noisy. Mrs. Knapp (furiously): 'I've run out of patience! If this takes any longer, we will make up for the lost time at the end of the lesson!' It gets a little quieter. Mrs. Knapp: 'We will read a short story, now.' A student: 'Who cares?'.

Imagine that many of Mrs. Knapp's lessons are just like that. What advice would you give Mrs. Knapp in order to improve her situation in the classroom? 


\section{Appendix C}

\section{Excerpt of the coding scheme for vignette 2}

\begin{tabular}{|c|c|c|}
\hline Categories & Code & Points \\
\hline $\begin{array}{l}\text { Not codable: too vague or wrong answers: } \\
\text { Too vague: Help Tim (no further specification as to how) } \\
\text { Wrong answer: Systematically ignore Tim's behaviour (although ignoring a student's } \\
\text { misbehavior can be useful in some situations, e.g. minor disruptions, it is not useful in the } \\
\text { present situation because Tim punches his classmates) } \\
\ldots\end{array}$ & 998 & 0 \\
\hline $\begin{array}{l}\text { Focus on Tim's positive behaviours/notice positive behaviours and reinforce them (e.g. } \\
\text { Token system); do not only focus on his negative behaviours (e.g. disruptions, swear } \\
\text { words) } \\
\text { (why: praise has proven to be more effective than punishment alone; aggressive students } \\
\text { often get negative feedback, only) }\end{array}$ & 1 & 1 \\
\hline$\ldots$ & 2 & 1 \\
\hline $\begin{array}{l}\text { Take time and talk to Tim about his problems after lesson in a more private setting } \\
\text { (why: do not embarrass him in front of the class, do not disrupt the lesson for a longer time, } \\
\text { be able to prepare oneself for the talk) } \\
\text { (half a point because answer is principally correct but not specific to Tim and his individual } \\
\text { problem; answer would apply to many high-needs students) }\end{array}$ & 3 & 0.5 \\
\hline$\ldots$ & 4 & 0.5 \\
\hline
\end{tabular}

Funding Open Access funding enabled and organized by Projekt DEAL. This research did not receive any specific grant from funding agencies in the public, commercial, or not-for-profit sectors.

Data availability Access to the data and the study material can be requested from the first author via e-mail.

\section{Declarations}

Conflict of interest We have no conflict of interest to declare.

Ethical approval Data collection followed the standards of the German Psychological Society (DGPs). Given the type of data collected (i.e. participation in the study did not cause any conceivable harm or discomfort for the participants that exceed their everyday experiences; research was conducted on common teaching methods in higher education), no ethical approval was considered necessary according to the guidelines at that time (2017). Participation was voluntary and participants gave informed consent to participate in the study. The data contains no personal or personally identifiable information.

Open Access This article is licensed under a Creative Commons Attribution 4.0 International License, which permits use, sharing, adaptation, distribution and reproduction in any medium or format, as long as you give appropriate credit to the original author(s) and the source, provide a link to the Creative Commons licence, and indicate if changes were made. The images or other third party material in this article are included in the article's Creative Commons licence, unless indicated otherwise in a credit line to the material. If material is not included in the article's Creative Commons licence and your intended use is not permitted by statutory regulation or exceeds the permitted use, you will need to obtain permission directly from the copyright holder. To view a copy of this licence, visit http://creativecommons.org/licenses/by/4.0/. 


\section{References}

Allen, J. M. (2009). Valuing practice over theory: How beginning teachers re-orient their practice in the transition from the university to the workplace. Teaching and Teacher Education, 25(5), 647-654. https://doi.org/10.1016/j.tate.2008.11.011

Augsdörfer, A., \& Casper, M. (2018). Closing the theory-practice gap: Employing authenticvideo-taped lessons in vocational teacher education. In C. Nägele \& B. E. Stalder (Eds.),Trends in vocational education and training research. Proceedings of the European Conference on Educational Research (ECER), Vocational Education and Training Network (VETNET) (pp. 33-43). https://doi.org/10.5281/ zenodo.1319622

Dicke, T., Parker, P. D., Marsh, H. W., Kunter, M., Schmeck, A., \& Leutner, D. (2014). Self-efficacy in classroom management, classroom disturbances, and emotional exhaustion: A moderated mediation analysis of teacher candidates. Journal of Educational Psychology, 106(2), 569-583. https://doi.org/ $10.1037 / \mathrm{a} 0035504$

Bacon, D. (2004). The contributions of reliability and pretests to effective assessment. Practical Assessment, Research \& Evaluation, 9(3), 1-8.

Berelson, B. (1952). Content analysis in communication research. Free Press.

Berger, R., \& Hänze, M. (2015). Impact of expert teaching quality on novice academic performance in the jigsaw cooperative learning method. International Journal of Science Education, 37(2), 294-320. https://doi.org/10.1080/09500693.2014.985757

Blomberg, G., Renkl, A., Sherin, M. G., Borko, H., \& Seidel, T. (2013). Five research-based heuristics for using video in pre-service teacher education. Journal for Educational Research Online, 5(1), 90-114.

Blömeke, S., Felbrich, A., Müller, C., Kaiser, G., \& Lehmann, R. (2008). Effectiveness of teacher education. State of research, measurement issues and consequences for future studies. The International Journal on Mathematics Education, 40(5), 719-734. https://doi.org/10.1007/s11858-008-0096-X

Bretz, S. L., \& McClary, L. (2014). Students' understandings of acid strength: How meaningful is reliability when measuring alternative conceptions? Journal of Chemical Education, 92(2), 212-219.

Bronkhorst, L.H. (2013). Research-based teacher education: Interactions between research and teaching (Doctoral dissertation, Dutch Interuniversity Center for Educational Sciences, the Netherlands). Retrieved November 11, 2019, fromhttps://dspace.library.uu.nl/bitstream/handle/1874/282740/bronk horst.pdf?sequence $=1$

Brown, J. S., Collins, A., \& Duguid, P. (1989). Situated cognition and the culture of learning. Educational Researcher, 18(1), 32-42. https://doi.org/10.3102/0013189X018001032

Chaplain, R. (2008). Stress and psychological distress among trainee secondary teachers in England. Educational Psychology, 28, 195-209. https://doi.org/10.1080/01443410701491858

De Jong, T., \& Ferguson-Hessler, M. G. (1996). Types and qualities of knowledge. Educational Psychologist, 31(2), 105-113. https://doi.org/10.1207/s15326985ep3102_2

Deci, E. L. \& Ryan, R. M. (2003). Intrinsic Motivation Inventory. Retrieved March 23, 2017, from http:// www.psych.rochester.edu/SDT/measures/intrins.html

Durik, A. M., \& Harackiewicz, J. M. (2007). Different strokes for different folks: How individual interest moderates the effects of situational factors on task interest. Journal of Educational Psychology, 99(3), 597-610. https://doi.org/10.1037/0022-0663.99.3.597

Emmer, E. T., Evertson, C. M., \& Anderson, L. (1980). Effective classroom management at the beginning of the schoolyear. Elementary School Journal, 80, 219-231. https://doi.org/10.1086/461192

Emmer, E. T., Evertson, C. M., \& Worsham, M. E. (2003). Classroom management for secondary teachers (6th ed.). Allyn and Bacon.

Fenstermacher, G. D. (1994). Chapter 1: The knower and the known: The nature of knowledge in research on teaching. Review of Research in Education, 20(1), 3-56.

Franke, U., \& Wecker, C. (2017, August). The role of experience-based and research-based knowledge in teachers' instructional decision-making. Paper presented at the 17th Biennial conference of the European Association for Research on Learning and Instruction (EARLI), Tampere, Finnland.

Goeze, A., Zottmann, J. M., Vogel, F., Fischer, F., \& Schrader, J. (2014). Getting immersed in teacher and student perspectives? Facilitating analytical competence using video cases in teacher education. Instructional Science, 42(1), 91-114. https://doi.org/10.1007/s11251-013-93043

Gold, B., Förster, S., \& Holodynski, M. (2013). Evaluation eines videobasierten Trainingsseminars zur Förderung der professionellen Wahrnehmung von Klassenführung im Grundschulunterricht [Evaluation of a video-based training to foster the professional vision of classroom management in primary school]. Zeitschrift Für Pädagogische Psychologie, 27(3), 141-155. https://doi.org/10.1024/10100652/a000100 
Gold, B., \& Holodynski, M. (2015). Development and construct validation of a situational judgment test of strategic knowledge of classroom management in elementary schools. Educational Assessment, 20(3), 226-248. https://doi.org/10.1080/10627197.2015.1062087

Gruber, H., Mandl, H., \& Renkl, A. (2000). Was lernen wir in Schule und Hochschule: Träges Wissen? [What do we learn in high school and university: inert knowledge?]. In M. Heinz \& J. Gerstenmaier (Eds.), Die Kluft zwischen Wissen und Handeln. Empirische und theoretische Lösungsansätze (pp. 139-156). Hogrefe.

Harackiewicz, J. M., \& Knogler, M. (2017). Interest: Theory and application. In A. J. Elliot, C. S. Dweck, \& D. S. Yaeger (Eds.), Handbook of Competence and Motivation: Theory and Application (2nd ed., pp. 334-352). Guilford Publications.

Hattie, J. (2009). Visible learning: A synthesis of over 800 meta-analyses relating to achievement. Routledge.

Hellermann, C., Gold, B., \& Holodynski, M. (2015). Förderung von Klassenführungsfähigkeiten im Lehramtsstudium. Die Wirkung der Analyse eigener und fremder Unterrichtsvideos auf das strategische Wissen und die professionelle Wahrnehmung. [Promotion of classroom management skills in pre-service teacher education. The impact of analyzing one's own and other's classroom videos on strategic knowledge and professional vision]. Zeitschrift Für Entwicklungspsychologie Und Pädagogische Psychologie, 47, 97-109. https://doi.org/10.1026/0049-8637/a000129

Hidi, S., \& Renninger, K. A. (2006). The four-phase model of interest development. Educational Psychologist, 41, 111-127. https://doi.org/10.1207/s15326985ep4102_4

Hmelo-Silver, C. E. (2004). Problem-based learning: What and how do students learn? Educational Psychology Review, 16(3), 235-266. https://doi.org/10.1023/B:EDPR.0000034022.16470.f3

Hmelo-Silver, C. E., Derry, S. J., Bitterman, A., \& Hatrak, N. (2009). Targeting transfer in a STELLAR PBL course for pre-service teachers. The Interdisciplinary Journal of Problem-Based Learning, 3(2), 24-42. https://doi.org/10.7771/1541-5015.1055

Khasinah, S. (2017). Managing disruptive behavior of students in language classroom. Englisia: Journal of Language, Education, and Humanities, 4(2), 79-89. https://doi.org/10.22373/ej.v4i2.1661

Korpershoek, H., Harms, T., de Boer, H., van Kuijk, M., \& Doolaard, S. (2016). A meta-analysis of the effects of classroom management strategies and classroom management programs on students' academic, behavioral, emotional, and motivational outcomes. Review of Educational Research, 86(3), 643-680. https://doi.org/10.3102/0034654315626799

Korthagen, F., \& Kessels, J. (1999). Linking theory and practice: Changing the pedagogy of teacher education. Educational Researcher, 28(4), 4-17. https://doi.org/10.3102/0013189X028004004

Kounin, J. S. (1970). Discipline and group management in classrooms. Holt, Rinehart \& Winston.

Kramer, C., König, J., Kaiser, G., Ligtvoet, R., \& Blömeke, S. (2017). Der Einsatz von Unterrichtsvideos in der universitären Ausbildun: Zur Wirksamkeit video- und transkriptgestützter Seminare zur Klassenführung auf pädagogisches Wissen und situationsspezifische Fähigkeiten angehender Lehrkräfte. [The implementation of videos in university teacher education: On the effectiveness of video- and transcript-based courses about classroom management on pre-service teachers' pedagogical knowledge and situational skills]. Zeitschrift Für Erziehungswissenschaft, 20(1), 137-164. https://doi.org/10.1007/s11618-017-0732-8

Krammer, K. (2014). Fallbasiertes Lernen mit Unterrichtsvideos in der Lehrerinnen- und Lehrerbildung. [Case-based learning with videos in teacher education]. Beiträge Zur Lehrerinnen- Und Lehrerbildung, 32(2), 164-175.

Krapp, A. (2010). Interesse. In D. H. Rost (Ed.), Handwörterbuch Pädagogische Psychologie [Handbook of educational psychology] (pp. 311-323). Beltz.

Krippendorff, K. (1989). Content analysis. In E. Barnouw, G. Gerbner, W. Schramm, T. L. Worth, \& L. Gross (Eds.), International encyclopedia of communication (Vol. 1, pp. 403-407). Oxford University Press.

Landrum, T. J., \& Kauffman, J. M. (2006). Behavioural approaches to classroom management. In C. M. Everton \& C. S. Weinstein (Eds.), Handbook of classroom management: Research, practice, and contemporary issues. Erlbaum.

Leikin, R., \& Levav-Waynberg, A. (2007). Exploring mathematics teacher knowledge to explain the gap between theory-based recommendations and school practice in the use of connecting tasks. Educational Studies in Mathematics, 66(3), 349-371. https://doi.org/10.1007/s10649-006-9071-z

Marzano, R. J., Marzano, J. S., \& Pickering, D. J. (2003). Classroom management that works: Researchbased strategies for every teacher. Association for Supervision and Curriculum Development.

McDonald, R. P. (1999). Test theory: A unified treatment. Lawrence Erlbaum Associates.

Merseth, K. K. (1996). Cases and case methods in teacher education. In J. Sikula, T. J. Buttery, \& E. Guyton (Eds.), Handbook of research on teacher education (2nd ed., pp. 722-744). Macmillan. 
Moreno, R., \& Valdez, A. (2007). Immediate and delayed effects of using a classroom case exemplar in teacher education: The role of presentation format. Journal of Educational Psychology, 99(1), 194-206. https://doi.org/10.1037/0022-0663.99.1.194

Mostert, M. P. (2007). Challenges of case-based teaching. The Behavior Analyst Today, 8(4), 434-442. https://doi.org/10.1037/h0100632

Nolting, H.-P. (2002). Störungen in der Schulklasse. Ein Leitfaden zur Vorbeugung und Konfliktlösung. Beltz.

Palmer, D. (2004). Situational interest and the attitudes towards science of primary teacher education students. International Journal of Science Education, 26(7), 895-908. https://doi.org/10.1080/ 0950069032000177262

Potvin, P. (2013). Proposition for improving the classical models of conceptual change based on neuroeducational evidence: conceptual prevalence. Neuroeducation, 1(2), 16-43. https://doi.org/10. 24046/neuroed.20130201.16

Reips, U. D. (2000). The Web experiment method: Advantages disadvantages and solutions. Psychological experiments on the Internet (pp. 89-117). Academic Press.

Renkl, A., Mandl, H., \& Gruber, H. (1996). Inert knowledge: Analyses and remedies. Educational Psychologist, 31, 115-121. https://doi.org/10.1207/s15326985ep3102_3

Schelfhout, W., Dochy, F., Janssens, S., Struyven, K., Gielen, S., \& Sierens, E. (2006). Educating for learning-focused teaching in teacher training: The need to link learning content with practice experiences within an inductive approach. Teaching and Teacher Education, 22(7), 874-897. https://doi.org/10. 1016/j.tate.2006.04.003

Schiefele, U., \& Schaffner, E. (2015). Motivation. In E. Wild \& J. Möller (Eds.), Pädagogische Psychologie [Educational Psychology] (pp. 154-175). Springer.

Schrader, P. G., Leu, D. J., Kinzer, C. K., Ataya, R., Teale, W. H., \& Labbo, L. D. (2003). Using internet delivered video cases, to support pre-service teachers' understanding of effective early literacy instruction: An exploratory study. Instructional Science, 31(4/5), 317-340. https://doi.org/10.1023/A:10246 90111227

Sherin, M. G. (2007). The development of teachers' professional vision in video clubs. In R. Goldman, R. Pea, B. Barron, \& S. J. Derry (Eds.), Video research in the learning sciences (pp. 383-395). Erlbaum.

Shulman, L. (1987). Knowledge and teaching: Foundations of the new reform. Harvard Educational Review, 57(1), 1-23. https://doi.org/10.17763/haer.57.1.j463w79r56455411

Siebert, C. J. (2005). Promoting preservice teachers' success in classroom management by leveraging a local union's resources: A professional development school initiative. Education, 125(3), 385-393.

Stürmer, K., Könings, K. D., \& Seidel, T. (2013). Declarative knowledge and professional vision in teacher education: Effect of courses in teaching and learning. British Journal of Educational Psychology, 83(3), 467-483. https://doi.org/10.1111/j.2044-8279.2012.02075.x

Syed, M., \& Nelson, S. C. (2015). Guidelines for establishing reliability when coding narrative data. Emerging Adulthood, 3(6), 375-387. https://doi.org/10.1177/2167696815587648

Syring, M., Bohl, T., Kleinknecht, M., Kuntze, S., Rehm, S., \& Schneider, J. (2016). Fallarbeit als Angebot - fallbasiertes Lernen als Nutzung. Empirische Ergebnisse zur kognitiven Belastung, Motivation und Emotionen bei der Arbeit mit Unterrichtsfällen. [Case-based learning. Empirical results on the cognitive, motivational, and emotional load when studying with cases]. Zeitschrift Für Pädagogik, 1, 86-108. https://doi.org/10.3262/ZP1601086

Thistlethwaite, J. E., Davies, D., Ekeocha, S., Kidd, J. M., MacDougall, C., Matthews, P., Purkis, J., \& Clay, D. (2012). The effectiveness of case-based learning in health professional education. A BEME systematic review: BEME Guide No 23. Medical Teacher, 34(6), 421-444. https://doi.org/10.3109/01421 59X.2012.680939

University of Münster (2020). ViU: Early Science.Retrieved November 6, 2020, from https://www.unimuenster.de/Koviu/

Veenman, S. (1984). Perceived problems of beginning teachers. Review of Educational Research, 54, 143178. https://doi.org/10.2307/1170301

Wigfield, A., \& Eccles, J. (2000). Expectancy-value theory of achievement motivation. Contemporary Educational Psychology, 25, 68-81. https://doi.org/10.1006/ceps.1999.1015

Yadav, A., Phillips, M., Lundeberg, M., Koehler, M., Hilden, K., \& Dirkin, K. H. (2011). If a picture is worth a thousand words is video worth a million? Differences in affective and cognitive processing of video and text cases. Journal of Computing in Higher Education, 23(1), 15-37. https://doi.org/10. 1007/s12528-011-9042-y

Zeichner, K. (1980). Myths and realities: Field-based experiences in pre-service teacher education. Journal of Teacher Education, 31(6), 45-55. 
Zottmann, J. M., Stegmann, K., Strijbos, J. W., Vogel, F., Wecker, C., \& Fischer, F. (2013). Computersupported collaborative learning with digital video cases in teacher education: The impact of teaching experience on knowledge convergence. Computers in Human Behavior, 29(5), 2100-2108. https://doi. org/10.1016/j.chb.2013.04.014

Publisher's Note Springer Nature remains neutral with regard to jurisdictional claims in published maps and institutional affiliations. 